\title{
Better than Nothing?: Consequence of Incomplete Treatment of COVID-19
}

\author{
Yasunori Fujita $^{1}$ \\ ${ }^{1}$ Keio University, Japan \\ Correspondence: Yasunori Fujita, Ph.D, Professor of Economics, Keio University, Japan. E-mail: \\ yfujita@true.ocn.ne.jp
}

Received: September 2, 2021

Accepted: September 12, 2021

Online Published: October 5, 2021

doi:10.5430/bmr.v10n3p11

URL: https://doi.org/10.5430/bmr.v10n3p11

\begin{abstract}
With seemingly no end to the global pandemic in sight, high expectations are growing for the development of medicines to treat COVID-19, in addition to the vaccination which has been carried out recently. In Japan also, development of such medicines is accelerating and now four COVID-19 medicines have been approved.

There is, however, concern that the COVID-19 medicines are not always effective, so that, in the present paper, we investigate the consequence of incomplete treatment of COVID-19-infected patients by constructing a simple intertemporal theoretical model. Main result we obtained is that incomplete treatment of infected patients increases number of the infected people, which is equivalent to say "worse than nothing".
\end{abstract}

Keywords: development of medicines to treat COVID-19, failure probability of treatment, steady state number of the infected individuals, transmission rate of the coronavirus, worse than nothing.

\section{Introduction}

With seemingly no end to the global pandemic in sight, high expectations are growing for the development of medicines to treat COVID-19, in addition to the vaccination which has been carried out recently. In Japan also, development of such medicines is accelerating and now four COVID-19 medicines have been approved.

There is, however, concern that the COVID-19 medicines are not always effective, so that, in the present paper, we investigate the consequence of incomplete treatment of COVID-19-infected patients by constructing a simple intertemporal theoretical model, extending theoretical models such as Guo (2020), Fujita (2020a,b,c) and so on. The model of the present paper is also inspired by numerous empirical studies, which revealed impacts of the COVID-19 on various economic aspects such as consumption, stock market, uncertainty, tax policy, leadership styles and so on (Baker, Bloom, Davis, Kost, Sammon, \& Viratyosin, 2020; Baker, Farrokhnia, Meyer, Pagel, \& Yannelis, 2020; Baker, Bloom, Davis, \& Terry, 2020; Watanabe, 2020; Bandara \& Weerasooriya, 2021; Ramadhanti \& Kularajasingham, 2021).

The question we pose here is whether we can prevent the spread of COVID-19 by the treatment that is not necessarily complete. Different from Fujita (2021), which investigated the consequence of prevention measures such as vaccination, the present paper focuses on the treatment of the patients who had positive PCR tests.

Structure of this paper is as follows. Section 2 lays out the basic model and section 3 derives number of the infected individuals in the steady state. Concluding remarks are made in section 4.

\section{Method}

Let us consider an intertemporal economy where time passes continuously and the time horizon is infinite. The economy consists of $N$ individuals, of whom $n(t)$ individuals in period $t$ are infected with the coronavirus. For the sake of simplicity, we assume that all the infected individuals do not present symptoms and that $x$ individuals, whether they are infected or not, randomly take PCR tests in every period.

In the present paper, those who tested positive get treatments, which are incomplete in a sense that failure probability of the treatment is $p \times 100 \%$, i.e., $p \times 100 \%$ of the positive individuals remain positive even after getting treatments. We also assume that those who were treated successfully can be infected again in the same period. In the setting of the 
present paper, number of those who are infected and take PCR tests is $\frac{n(t)}{N} x$, so that number of those who were treated unsuccessfully and hence are still positive after the treatment is $\frac{p n(t) x}{N}$, while number of those who were treated successfully (and hence are not positive anymore after the treatment) but can be infected again in the same period is $\frac{(1-p) n(t) x}{N}$.

Thus, we can classify those who are infected as in Figure 1.

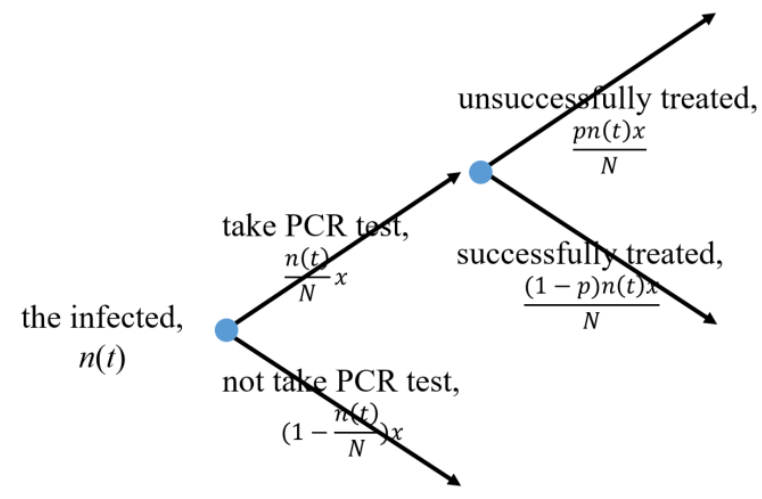

Figure 1. Classification of the infected

\section{Results}

In the present paper, we assume each of the treated-but-still-positive individuals, thinking falsely that they are not infected any more, transmits the virus to $\alpha$ individuals, of whom a fraction of $\left\{1-\frac{n(t)-\frac{(1-p) n(t) x}{N}}{N}\right\}$ is newly infected, since among the $n(t)$ individuals who were infected, $\frac{(1-p) n(t) x}{N}$ can be infected again by the above assumption. We also assume, for the simplicity of analysis, that those who did not receive PCR tests keep avoiding the Three Cs carefully, and hence do not transmit, even if they are infected, the virus to any individuals.

Thus, we can express the motion of number of the infected individuals as

$n(t+1)=n(t)-(1-p) \frac{n(t)}{N} x+\frac{p n(t) x}{N} \alpha\left\{1-\frac{n(t)-\frac{(1-p) n(t) x}{N}}{N}\right\}$.

Letting $n^{*}$ denote the steady state number of the infected individuals and substituting $n(t+1)=n(t)=n^{*}$ into equation $(1)$, we have the condition $n^{*}$ should satisfy as

$(1-p) \frac{n^{*}}{N} x=\frac{p n^{*} x}{N} \alpha\left\{1-\frac{n^{*}-(1-p) \frac{n^{*}}{N} x}{N}\right\}$.

By solving $n^{*}$ with respect to (2), we get

$n^{*}=\frac{\left(1-\frac{1-p}{p \alpha}\right) N}{1-(1-p) \frac{x}{N}}$ 
Since the graph of (3) is drawn on the $x-n *$ plane as in Figure 2, we have the following proposition.

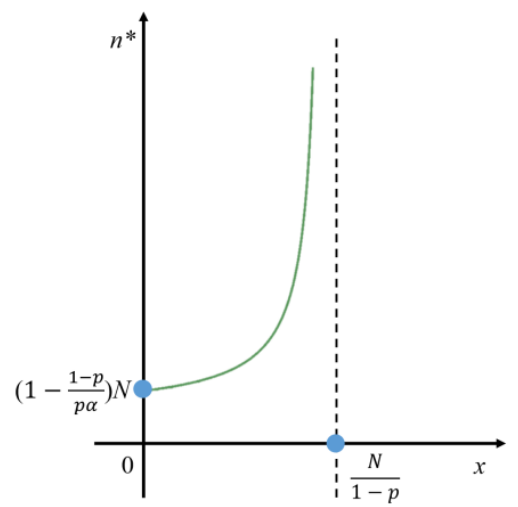

Figure 2: Graph of $n^{*}$ as a function of $x$

\section{Proposition: The steady state number of the infected people, $n *$, is an increasing function of the number of treatment of the infected individuals, $x$.}

From Proposition, we can say that the more we treat the infected individuals, the more the number of the infected people is, if the treatment is incomplete.

\section{Discussion}

The present study investigated theoretically the consequence of incomplete treatment of COVID-19-infected individuals, to obtain the result that the incomplete treatment of the infected individuals always increases the number of the infected people, which is equivalent to say "worse than nothing".

In the present paper, we assumed away the economic aspect in order to focus on the treatment of COVID-19-infected individuals. Thus, it is necessary to examine the robustness of our results in a more general framework that incorporates the economic activities. It is also of interest to investigate the compound effects of the vaccination and the treatment of COVID-19. We will undertake such analyses next.

\section{Acknowledgements}

The author is thankful to anomymous referees for their valuable comments.

\section{References}

Baker S. R., Bloom, N., Davis, S. J., Kost, K. J., Sammon, M. C., \& Viratyosin, T (2020). The unprecedented stock market impact of covid-19. NBER Working Paper Series 26945. https://doi.org/10.3386/w26945

Baker, S. R., Farrokhnia R. A., Meyer, S., Pagel, M., \& Yannelis, C. (2020). How does household spending respond to an epidemic? Consumption during the 2020 Covid-19 pandemic. NBER Working Paper Series 26949. https://doi.org/10.3386/w26949

Baker, S. R., Bloom, N., Davis, S. J., \& Terry, S. J. (2020). COVID-induced economic uncertainty. NBER Working Paper Series 26983. https://doi.org/10.3386/w26983

Bandara, K. G. A. G., \& Weerasooriya, W. M. R. B. (2021). A study between the taxpayers' perception toward the tax policy changes and the tax compliance in Sri Lanka: A tax relief in response to the impact of Covid-19 epidemic, and its implications. Business, Management and Economics Research, 7(2), 52-64. https://doi.org/doi.org/10.32861/bmer.72.52.64

Fujita, Y. (2020a). When should we start the lockdown and how long should it be?, Modern Economy, 11, 1007-1011. https://doi.org/10.4236/me.2020.115075

Fujita, Y. (2020b). How much should government compensate firms for suspension of their businesses in order to fight off the new coronavirus?, Theoretical Economics Letters, 10, 600-606. https://doi.org/10.4236/tel.2020.103038 
Fujita, Y. (2020c) How could we prevent spread of the coronavirus without deteriorating economy?, Modern Economy, 11, 1280-1287. https://doi.org/10.4236/me.2020.117091

Fujita, Y. (2021). Does vaccinations reduce the COVID-19 infection?, Archives of Business Research, forthcoming. https://doi.org/10.14738/abr.98.10608

Guo, Zi-Yi (2020). Noisy information, risk sharing, and international business cycles. Review of International Economics, Wiley Blackwell, 28(1), 209-234. https://doi.org/10.1111/roie.12447

Ramadhanti, T., Singh, J. S. K., \& Kularajasingham, J. (2021). Transactional and transformational leadership styles as predictors of employee performance during the Covid-19 crisis and the mediating role of organisational culture. Business, Management and Economics Research, 7(2), 39-51. https://doi.org/10.32861/bmer.72.39.51

Watanabe, T. (2020). The responses of consumption and prices in Japan to the COVID-19 crisis and the Tohoku earthquake. Working Paper Series, CARF-F-476.

\section{Copyrights}

Copyright for this article is retained by the author(s), with first publication rights granted to the journal.

This is an open-access article distributed under the terms and conditions of the Creative Commons Attribution license (http://creativecommons.org/licenses/by/4.0/). 